\title{
Problemas E Soluções Ambientais Causados Por Uma Empresa De Produção De Blocos De Grande Porte
}

\author{
Vânia Haddad Diego' \\ Walter Antonio da Silva Costa ${ }^{2}$ \\ Ricardo Camargo de Araujo \\ Maurício Pedro da Silva
}

\begin{abstract}
1. Vânia Haddad Diego vaniahaddad@yahoo.com.br é doutora pela USP - Universidade de São Paulo em Neurociências e Comportamento (2002), Mestre na área de Teoria e Pesquisa (1997), Especialista em Ecologia e Graduada em Ciências Biológicas. É professora do ensino superior nos cursos de Engenharia de Produção, Mecatrônica, Gestão da Produção Industrial, da Qualidade e Ambiental. Tem experiência na área de pesquisa de campo e laboratório com confecção de equipamentos para testes de habilidades, e soluções de problemas ambientais com financiamento da Conservation International, Fapesp, CNPq e Capes. Orienta Projetos nas áreas: Ambiental e Tratamento de Resíduos, Engenharia Ambiental, Políticas Sociais e Ambientais, Análise de Projetos Ambientais e a Responsabilidade Social. Parecerista de projetos do CNPq.
\end{abstract}

\begin{abstract}
2. Walter Adasco. walter.adasco@gmail.com. é Mestre em Engenharia de Produção pela UNESP-FEB/SP (2008); Especialista em Gestão Empresarial CEETEPS-IPEN/SP. Bacharelado em Engenharia de Produção. Graduado em Gestão da Produção Industrial e em Gestão de Qualidade, Consultor e Professor nas áreas de Administração e Engenharia de Produção, com ênfase em Projetos, Processos e Logística. Atua nas áreas de armazenagem, movimentação, racionalização de processos e aplicação de sistemas de informação.
\end{abstract}

\begin{abstract}
3. Ricardo Camargo de Araujo, ricardo.ca@bol.com.br é mestre em administração. Analista financeiro e consultor. Professor do ensino superior nos cursos de Administração de Empresas, Gestão de Recursos Humanos e Gestão Ambiental nas faculdades UNIP e ENIAC de Guarulhos onde orienta Projeto integrador e TCC. É Profissional da área de Finanças. Coordenador e Diretor na área financeira e gestão em diversas faculdades de São Paulo.

Engenharia de Produção - Faculdade ENIAC, Guarulhos/SP, Brasil
\end{abstract}

\begin{abstract}
4.Mauricio Pedro da Silva, maurio_psilva@ig.com.br. é pesquisador da Fábrica de artigos do grupo Eniac, Editor Técnico da Revista ENIAC PESQUISA, especialista em OJS - open Journal System e especialista por notória especialidade em RH. É Pósgraduado em Administração de Recursos Humanos na Universidade São Judas Tadeu (1997) e em docência do Ensino Superior (2005). Professor do ensino superior nos cursos de Administração de Empresas, Gestão de Recursos Humanos e Gestão Ambiental nas faculdades UNIP e ENIAC de Guarulhos, onde orienta Projeto integrador e TCC. É Profissional da área de Administrativa, com ênfase em Administração de RH e Finanças.
\end{abstract}

\section{Resumo}

No presente trabalho estaremos avaliando problemas e soluções relacionadas a poluição ambiental causadas por uma empresa de grande porte de Guarulhos que trabalha com a produção de blocos. Devido ao grande crescimento populacional na cidade de Guarulhos ocorreu também um crescimento na construção civil e na utilização dos produtos fabricados pela empresa em questão. Sendo assim o crescimento da empresa acompanhado da conscientização socioambiental poderá trazer vantagens econômicas e no marketing social e ambiental para a empresa.

Palavras-chave: Produção de Blocos; Poluição Ambiental; Gestão Ambiental. 


\section{Introdução}

A cidade de Guarulhos registrou em duas décadas um crescimento de 40,26\% no Índice de Desenvolvimento Humano Municipal IDHM, analisando esse crescimento populacional devemos pensar no desenvolvimento sustentável da cidade. Com o crescimento populacional em Guarulhos na ultima década houve uma grande alta de empreendimentos na cidade, isso nos leva a nos preocupar com a nossa sustentabilidade e o meio ambiente, pois estes serviços geram muitos resíduos que poluem o meio ambiente. Com este aumento e crescimento nas construções também aumenta a produção de blocos, utilizados na construção.

É um ciclo de crescimento constante, quanto mais a obra desenvolve, mais serviços são contratados, mais empregos gerados e mais aumento do desenvolvimento das empresas prestadoras de serviços (RIBEIRO e MORELLI, 2009).

A empresa de blocos foco deste trabalho possui 42 anos no mercado. Buscando manter o seu sigilo a chamaremos de Alfa. Situa-se desde 1971 no município de Guarulhos/SP. Dessa forma a Alfa constituiu-se como empresa familiar no qual tias e sobrinhos eram os responsáveis pela produção de blocos. Com o tempo, a empresa expandiu-se e buscou uma área maior para suas operações. Com a mudança a empresa adquiriu novos maquinários que proporcionou crescimento, passando a produzir vários tipos de blocos, em quantidades maiores e de melhor qualidade.

A produção de blocos do tipo estrutural, bem como os chamados compensadores e também os pisos intertravados atraíram a atenção de construtoras. Assim, a Alfa conseguiu se destacar e avançou frente a concorrência, tornando-se líder em seu segmento. Nos dias atuais a Alfa caracterizase por ser uma empresa de grande porte, contando com aproximadamente 200 funcionários. No que tange a maquinários, a Alfa possui quatro máquinas Besser para a produção de blocos, além de embaladeiras eletrônicas em filme stretch e uso de paletes e empilhadeiras para movimentação dos produtos unitizados. Neste contexto, a empresa conta com 12 empilhadeiras e duas pás carregadoras. Conta ainda com uma frota de 80 caminhões agregados para atendimento de cerca de 40 milhões de blocos por ano.

Neste trabalho visamos levantar problemas de poluição ambiental e tem como base um estudo de caso de uma fábrica de blocos e pavimentos, os processos 
produtivos em fábricas deste tipo geram resíduos e caso não seja promovida uma boa gestão e destinação final, estes resíduos podem acabar poluindo o meio ambiente, nomeadamente o solo, o ar e possíveis corpos d'água do entorno. Além disso, é importante ressaltar a poluição sonora decorrente do processo produtivo. O desenvolvimento de um projeto de gestão ambiental em uma organização como esta, pode contribuir com práticas ambientalmente saudáveis, com menores impactos sobre o meio ambiente, preservando a saúde dos funcionários e melhorando a imagem da empresa perante o mercado.

\section{Desenvolvimento}

\section{Poluição Ambiental}

Tudo que está em excesso e prejudique a saúde, a segurança e o bem-estar da população é considerado poluição (FELLENBERG, 2009).

A poluição pode ser definida com alterações indesejadas nas características físicas, químicas ou ainda biológicas dos compartimentos aéreos, aquáticos e terrestres, podendo ser estas alterações prejudiciais à saúde e vida humana e de outros animais, à qualidade de vida, aos processos industriais e aos aspectos culturais (SHING, 2006).

O Congresso Nacional, na Lei n. 6.938 de 31 de agosto de 1981, da Política Nacional do Meio Ambiente, em seu Artigo $3^{\circ}$, inciso III, define poluição como sendo:

\begin{abstract}
A degradação da qualidade ambiental resultante de atividades que direta ou indiretamente: (a) prejudiquem a saúde, a segurança e o bem-estar da população; (b) criem condições adversas às atividades sociais e econômicas; (c) afetem desfavoravelmente a biota; (d) afetem as condições estéticas ou sanitárias do meio ambiente; (e) lancem matérias ou energia em desacordo com os padrões ambientais estabelecidos (BRASIL, 1981, não paginado).
\end{abstract}

Por sua vez, o Conselho Nacional do Meio Ambiente (CONAMA), em sua Resolução n. 1, de 23 de janeiro de 1986, Artigo $1^{\circ}$, com o intuito de complementar a Política Nacional de Meio Ambiente, define o seguinte:

Considera-se impacto ambiental qualquer alteração das propriedades físicas, químicas e biológicas do meio ambiente, causada por qualquer forma de matéria ou energia resultante das atividades humanas que, direta ou indiretamente, afetam: (I) a saúde, a segurança e o bem-estar da população; (II) as atividades sociais e econômicas; (III) a biota; (IV) as condicõoes estéticas e sanitárias do meio ambiente; $(V)$ a qualidade dos recursos ambientais (CONAMA, 2012, p. 922).

\section{Produção de Blocos}

Os blocos são produzidos a partir de matérias-primas como areia, pedrisco e pó de pedra, além de cimento e água. Quando 
os caminhões que transportam a matériaprima chegam à fábrica, esta matéria-prima é inspecionada, e se for aprovada, é disposta no pátio. Neste lugar, existe um mecanismo de vibração subterrânea, que faz com que a matéria-prima caia por dutos que irão conduzí-la a uma esteira rolante, que por sua vez, irá conduzir esta matéria-prima para silos. Nestes silos, uma vez presentes todas as matérias-primas na quantidade adequada, será feita e misturada a massa. Esta massa é dirigida para as prensas, onde estão as formas de blocos. Posteriormente, estes blocos moldados são encaminhados para estufas para secagem. Após o processo de secagem os blocos são empilhados, embalados e paletizados, sendo dispostos no pátio onde é feito o carregamento dos caminhões.

\section{A Poluição no Contexto da Produção de Blocos}

As atividades decorrentes da fabricação de blocos e pavimentos, assim como muitas outras atividades industriais, podem gerar poluição e, consequentemente, impactos ambientais. O presente trabalho pretende atuar como um diagnóstico, visando identificar quais são os tipos de resíduos, e as formas de poluição que este processo produtivo pode gerar. Para tanto, é necessário conhecer o processo produtivo e suas etapas, desde a chegada da matériaprima até a entrega do produto ao cliente, analisar os maquinários e produtos utilizados, os resíduos gerados, possibilitando a detecção de pontos críticos, em termos de agressão ao meio ambiente.

A partir do conhecimento acerca das atividades envolvidas na produção de blocos, a presente investigação trabalha com a hipótese de que esta fabricação gera poluição ambiental. Por este motivo, após apresentadas as definições de poluição e de impacto ambiental, é importante que seja feita uma breve descrição dos tipos de poluição.

\section{Poluição do Ar}

Conforme Valle (2009), a contaminação do ar pode ser decorrente de fontes estacionárias, também chamadas de fontes fixas, tais como chaminés de indústrias e na carga e descarga de produtos voláteis, ou de fontes móveis, tais como veículos, obras de construção civil, atividades de mineração. Valle (2009) ainda diz que a intensidade e as características da poluição do ar são fortemente influenciadas pela topografia e as condições meteorológicas (velocidade e direção dos ventos, índices pluviométricos, variações de pressão etc.).

Os poluentes atmosféricos são substâncias resultantes de uma gama de 
atividades que promovem a deterioração da qualidade natural do ar (ALMEIDA, 1999). Estes poluentes podem ser materiais gasosos ou particulados. No presente estudo, será enfocada a poeira, decorrentes do processo produtivo. A poeira é um material particulado, e é considerada um poluente primário, ou seja, um poluente que já é emitido diretamente na atmosfera sob esta forma, a partir de fontes identificáveis (SINGH, 2006).

No que diz respeito à poluição atmosférica, a legislação brasileira obedece a diversas resoluções, e leis, merecendo destaque a Resolução CONAMA n. 5, de 05 de junho de 1989. Esta Resolução dispõe sobre o Programa Nacional de Controle da Poluição do Ar - PRONAR, que visa uma melhoria na qualidade do ar, o atendimento aos padrões estabelecidos e o não comprometimento da qualidade do ar em áreas consideradas não degradadas (CONAMA, 2012). A elaboração do PRONAR foi motivada pelo acelerado crescimento urbano e industrial, o aumento da frota de veículos, o aumento da poluição atmosférica sobre os grandes centros urbanos, os reflexos negativos que esta poluição pode ter sobre a sociedade, a economia e o meio ambiente, visando, ainda, estabelecer estratégias para o controle, a preservação e a recuperação da qualidade do ar, já introduzidos na Política Nacional do Meio Ambiente, de 1981.

Augusto Guzzo Revista Acadêmica, 2014, № 13
Assim como outras atividades econômicas, como a mineração, a produção de blocos resulta na geração de grande quantidade de poeira, que são materiais particulados. De acordo com ANDRADE (2013), a poeira em suspensão é formada por partículas menores que $10 \mu \mathrm{m}$, que tendem a permanecer no ar por mais tempo, e a chamada poeira sedimentável, constituída por fracções maiores do que $10 \mu \mathrm{m}$, que, conforme o próprio nome já diz, tendem a sedimentar, ficando menos tempo no ar. Entretanto, é importante ressaltar que o mesmo a poeira sedimentável pode tornar-se poeira em suspensão, dependendo das condições.

Em condições climáticas mais secas, por exemplo, a poeira tende a ficar em suspensão. $\mathrm{O}$ mesmo ocorre quando há constante perturbação do solo onde ela se deposita. No caso da fábrica de blocos, esta poeira tende a depositar principalmente no pátio, onde há grande fluxo de veículos. Para o transporte de materiais, são utilizados muitos caminhões, empilhadeiras e pás carregadeiras, cujo funcionamento promove a ressuspensão dos materiais particulados, além de contribuir com a emissão de gases para a atmosfera.

Dentro dos galpões onde os blocos são produzidos, paletizados e embalados para serem entregues ao cliente, também há uma grande quantidade de poeira. Os blocos que se quebram, além de outros resíduos e www. fics. edu. br $\mathbf{5}$ 
fragmentos, e as sobras que comumente ocorrem, são depositados no chão, havendo funcionários responsáveis pela limpeza constante do ambiente, o que também colabora para que haja poeira em suspensão.

Para lidar com esta poluição do ar por poeira, a empresa adota a utilização de máscaras, um dos Equipamentos de Proteção Individual (EPI). Além disso, constantemente é feita a aspersão de água no solo e a aspiração da poeira nele presente, através da utilização de máquinas.

A empresa contrata periodicamente serviços de uma empresa para realizar análises visando avaliar os níveis de poeira presente no ar, em diversos setores da empresa. No último teste conduzido, em 2008, as amostragens realizadas não detectaram níveis acima dos limites de tolerância. Durante a condução do presente estudo, estavam sendo realizadas novas medições.

\section{Poluição do Solo}

Sabe-se que a produção de blocos e pavimentos gera resíduos sólidos, tais como produtos defeituosos, restos de produtos usados em testes ou resíduos gerados durante o processo produtivo em si. Todos estes materiais são dispostos em um espaço da fábrica a céu aberto chamado de entulho. Conforme mencionado, também poderá ser encontrada no solo a poeira sedimentável.
É comum ainda observar manchas de óleo no solo em decorrência de vazamentos de veículos, tanto no pátio da empresa quanto em um ambiente externo, um terreno em frente à empresa, onde os caminhões que serão carregados ficam aguardando. Neste terreno, também é possível observar resíduos, tais como a poeira e fragmentos de blocos.

Para o processo de produção dos blocos, é necessário que estes logo após serem moldados na prensa sejam dispostos em uma estufa a $75^{\circ}$.C. O aquecimento das estufas é dado pelo funcionamento de quatro caldeiras movidas a óleo diesel, sendo possível observar também vazamento de óleo nas imediações das caldeiras.

A poeira deposita-se nas camadas mais superficiais do solo e, levando-se em consideração o intenso fluxo de caminhões e máquinas no pátio, o impacto maior da poeira será realmente sobre o ar. Entretanto, no que diz respeito ao óleo, este pode ser absorvido pelo solo, comprometendo a qualidade deste, uma vez que os hidrocarbonetos são compostos cuja toxicidade e nocividade ao meio ambiente estão bem documentados na literatura.

As medidas tomadas pela empresa com relação à poluição do solo abrangem a coleta do entulho por uma empresa terceirizada. A Alfa declara ainda que todo o pavimento dentro da empresa possui uma espessura de 
$20 \mathrm{~cm}$, propiciando a impermeabilização do solo, de maneira que não seria possível que o óleo infiltrasse no solo, contaminando-o. A empresa está investindo, atualmente, na compra de uma caldeira com funcionamento a gás, que substituirá as quatro caldeiras hoje em utilização, movidas a óleo asfáltico. Enquanto esta nova caldeira a gás não é comprada, o óleo usado nas caldeiras é posteriormente utilizado na lubrificação de equipamentos.

A empresa deve utilizar um 'kit mitigação’ é um kit que deve ser utilizado em caso de vazamento ou derramamento de óleo ou produtos perigosos, composto por materiais e ou equipamentos que absorvam o contaminante antes deste se infiltrar no solo, diminuindo o impacto ambiental. É composto por tonel de serragem, manta absorvente, massa para vedação de emergência, balde, pá, vassoura, saco plástico, mascara para vapores orgânicos, luvas de látex, óculos de proteção e tonel para colocar serragem e ou manta contaminada com óleo. $\mathrm{O}$ descarte deve ser destinado ao local devidamente regularizado segundo a legislação.

\section{Poluição da Água}

A empresa em questão não possui um sistema de emissão de resíduos para corpos d'água. Entretanto, conforme mencionado no solo encontram-se a poeira, o óleo, além de outros materiais dispostos na área de entulho da empresa. Quando chove, pode ocorrer a lixiviação destes materiais, que serão levados com a água da chuva e poderão atingir corpos d'água, como por exemplo um córrego que passa nas adjacências da empresa.

A empresa está investindo atualmente na instalação de grelhas dispostas pelo pátio para captação da água da chuva. Esta água será bombeada e filtrada para ser utilizada na preparação da massa para fabricar os blocos.

\section{Poluição Sonora}

A poluição sonora pode ser definida como um som ou ruído indesejado e/ou desagradável, liberados na atmosfera sem que sejam considerados os efeitos adversos que podem tem. Singh (2006), falando sobre a Índia, descreve um cenário muito parecido com o brasileiro. $\mathrm{O}$ autor relata que naquele país, a urbanização e a industrialização tornaram-se problemas que andam lado a lado, e a falta de planejamento urbano adequado resultou em áreas residenciais, comerciais e industriais todas misturadas.

É importante ressaltar, portanto, que a poluição sonora é uma ameaça à qualidade da saúde humana e ambiental, sendo o homem o seu principal causador, além outras inúmeras fontes poluidoras, tais como os carros, aviões, e as atividades industriais, que produzem ruídos que podem atingir a vizinhança, além dos próprios operários. A www. fics. edu. br 7 
poluição sonora não deixa resíduos, não tem efeito acumulativo sobre o meio ambiente, mas pode ter esse efeito sobre o homem, tem um raio de ação pequeno (local), e, por ser percebido somente pelo sentido da audição, muitas vezes acaba tendo seus efeitos subestimados pelas pessoas.

Atualmente, a legislação brasileira segue, entre outras, as Normas NBR-10151 e NBR10152 da Associação Brasileira de Normas Técnicas (ABNT), e a Resolução CONAMA n. 1, de 08 de março de 1990. A elaboração desta resolução baseou-se na deterioração da qualidade de vida associada à poluição, principalmente nos grandes centros urbanos, e estabelece que a emissão de ruídos deve respeitar a saúde e o sossego público, obedecendo os níveis considerados aceitáveis pela Norma NBR-10151 Avaliação do ruído em áreas habitadas visando o conforto da comunidade - e pela Norma NBR-10152 - Níveis de ruído para conforto acústico.

Singh (2006) destaca que conversas normais entre pessoas gira em torno dos 30 $60 \mathrm{~dB}$, e que ruídos acima dos $140 \mathrm{~dB}$ são considerados problemáticos, e prejudiciais à saúde humana. O constante contato com ruídos acima do suportável ao bem estar pode levar à perda auditiva pelo ruído (Perda Auditiva Induzida por Ruído - PAIR), que é uma patologia progressiva. Os efeitos causados pelo ruído são: trauma acústico, perda auditiva temporária e perda auditiva permanente, estresse, grande causador de mortes por parada cardíaca quando passa de 85 Db (FELLENBERG, 2009).

Em termos de ruídos, a empresa de blocos em questão está sujeita ao barulho dos caminhões que entram e saem durante todo o dia, trazendo material ou levando produto. Além disso, há o barulho das empilhadeiras e pás carregadeiras cujo fluxo também é constante.

A atividade das caldeiras requer $\mathrm{O}$ funcionamento de quatro compressores cuja emissão de ruídos também é elevada, bem como ocorre com as máquinas que são uma espécie de esteira rolante movidas a motor, que servem para levar a matéria-prima (areia, pedriscos e pó de pedra) até os silos onde é preparada a mistura para fazer os blocos.

Entretanto, as maiores fontes de ruído são as máquinas Besser, que são as prensas que moldam os blocos em si. A empresa possui quatro destas máquinas, que são operadas dentro de dois galpões, gerando grande quantidade de ruído audível de qualquer setor da empresa.

Testes de ruído conduzidos pela própria Alfa demontraram que em alguns setores operacionais, os níveis ultrapassam $85 \mathrm{~dB}$, que é o limite de tolerância. Nestes setores, para lidar com esta situação, a empresa em questão adota o uso de protetores auriculares, respeitando as regulamentações 
da Norma NR-6 da ABNT. Entretanto, é comum ver funcionários trabalhando sem a utilização deste EPI assim como outros também em questão, que leva a considerar que deveria haver uma maior fiscalização neste aspecto.

\section{Gestão Ambiental}

A gestão ambiental consiste em um conjunto de medidas e procedimentos que quando adequadamente utilizados permite a redução e o controle dos impactos ambientais decorrentes da implantação de um determinado empreendimento (VALLE, 2009). O ideal é que a gestão ambiental acompanhe todo o processo, desde a implantação do empreendimento até a posterioridade durante seu funcionamento (DONAIRE,2004; ANDRADE et al, 2006).

No presente estudo a empresa em questão já existe há quase 40 anos de modo que, para que haja uma gestão ambiental eficiente, deve-se proceder a chamada 'avaliação ambiental inicial', que irá permitir identificar problemas ambientais latentes e colher subsídios para elaborar uma política ambiental adequada, buscando pela melhoria contínua dos processos, visando a obtenção de selos ambientais, em regularidade com a série ISO 14000. De acordo com Valle (2009), a gestão do meio ambiente não deve ser vista como um problema a mais para a organização, uma vez que é fundamental Augusto Guzzo Revista Acadêmica, 2014, № 13 para seu desenvolvimento e sobrevivência. Em outras palavras, para que uma organização seja bem sucedida visando manter-se dentro das conformidades estabelecidas pela legislação e com boa competitividade no mercado. De acordo com este mesmo autor, a certificação pelas normas ISO 14000 deve fazer parte da estratégia de qualquer organização que pretenda manter-se competitiva.

$\mathrm{Na}$ cidade de Guarulhos podemos contar com a Proguaru que produz a reciclagem dos resíduos -RCC- da construção civil e resíduos gerados pela população, existem os pontos de entrega voluntária - PEVs- em diversos locais da cidade, quando a quantidade do material é inferior a $1 \mathrm{~m}^{3} \backslash$ dia são depositados nestes locais, porém quando os resíduos gerados pela construção civil são até $150 \mathrm{~m}^{3} \backslash$ dia a entrega é feita pelo contratante com prévio agendamento. Sabemos que a construção civil gera muitos resíduos tanto na execução, na manutenção ou na reforma, para que ocorra essa reciclagem a usina recebe somente aquele material que seja feito uma triagem antes do envio, são recolhidos somente os resíduos do tipo classe A como restos de tijolos, concreto em geral, bloco cerâmicos, rochas, argamassa, telhas, reboco etc. Com a reciclagem deste material a Proguaru utiliza para a fabricação de pré moldados, como tampas de boca de lobo, bancos e mesas de praças, e na execução de www. fics. edu. br 9 
serviços e obras públicas. Desta forma contribui para a preservação do meio ambiente, com a conservação dos recursos naturais, e promove o desenvolvimento urbano, com sustentabilidade ambiental. (PROGUARU,2013)

\section{Conclusão}

Concluímos que a melhor solução para mitigar os problemas ambientais causados pela produção empresa de blocos é ela trabalhar com uma gestão socioambiental integrando a produção com a área ambiental, segurança dos colaboradores e da população. Apresentando uma postura pró ativa dentro da organização, outro fator é a disponibilidade de recursos que a empresa direciona para a gestão ambiental pois sem o investimento fica difícil para reavaliar processos, modificar equipamentos e pesquisar novos produtos. Com certeza estes investimentos trazem vantagens econômicas a longo prazo, ambientais de conscientização e respeito ao meio ambiente e melhora a imagem da empresa.

\section{Referências}

ALMEIDA, Ivo T. A poluição atmosférica por material particulado na mineração a céu aberto. São Paulo: Departamento de Engenharia de Minas da Escola Politécnica da Universidade de São Paulo - USP, 1999 (Dissertação de
Mestrado apresentada ao Departamento de Engenharia de Minas da Escola Politécnica da Universidade de São Paulo). Disponível em:

$<$ http://www.teses.usp.br/teses/disponiveis /3/3134/tde-31012002-170628/pt-br.php>. Acesso em: 05 jun. 2014.

ANDRADE, Paula C. C. Impacto integrado de empreendimentos minerometalúrgicos em congonhas. Ouro Preto: Departamento de Engenharia de Minas da Escola de Minas da Universidade Federal de Ouro Preto UFOP, 2013 (Dissertação apresentada ao Programa de Pós-Graduação do Departamento de Engenharia de Minas da Escola de Minas da Universidade Federal de Ouro Preto). Disponível em:

$<$ http://www.repositorio.ufop.br/bitstream $/ 123456789 / 3437 / 1 /$ DISSERTA\%C3\%87 $\%$ C3\%83O_ImpactoIntegradoEmpreendim entos.pdf>. Acesso em: 05 jun. 2014.

ANDRADE, R. O. B. de; TACHIZAWA, Takeshy; CARVALHO, A. B. de. Gestão ambiental: enfoque estratégico aplicado ao desenvolvimento sustentável. São Paulo: Pearson Makron Books, 2006.

BRASIL. Lei n. 6.938, de 31 de agosto de 1981. Dispõe sobre a Política Nacional do Meio Ambiente, seus fins e mecanismos de formulação e aplicação, e dá outras providências. DOU - Diário Oficial da União [da República Federativa do Brasil], Brasilia, DF, 2 set. 1981. Disponível em: $<$ http://www.planalto.gov.br/ccivil_03/leis /16938compilada.htm>. Acesso em: 19 dez. 2013.

CONAMA - Conselho Nacional do Meio Ambiente (Brasil). Resoluções do Conama: Resoluções vigentes publicadas entre setembro de 1984 e janeiro de 2012. Ministério do Meio Ambiente. Brasília: MMA, 2012. Disponível em: <http://www.mma.gov.br/port/conama/pr ocessos/61AA3835/LivroConama.pdf>. Acesso em: 05 jun. 2014. 
DONAIRE, D. Gestão Ambiental na

Empresa. $2^{a}$ ed. São Paulo: Atlas, 2004.

FELLENBERG, G. Introdução aos

Problemas da Poluição Ambiental.São

Paulo: Editora EPU, 2006.

PROGUARU Disponível em

http://www.proguaru.com.br/site/recebime nto entulho 16.09.2013 (acesso em

26/07/2014)

RIBEIRO, D. V., MORELLI,M.R. Resíduos Sólidos- Problema ou Oportunidade. $1^{\mathrm{a}} \mathrm{Ed}$. Interciencia, 2009.

SINGH, Y. K. Environmental science. New Delhi: New Age International Publishers, 2006. Disponível em:

$<$ http://depositfiles.org/files/3bfd4zo16>. Acesso em: 19 dez. 2013.

VALLE, C. E. Qualidade ambiental - ISO 14000. 9. ed. São Paulo: Senac, 2009. 